\title{
Experiência na Coordenação de Área do PIBID da Licenciatura em Informática: Ensino de Computação na Escola Pública
}

\author{
Title: An experience in Coordinating the PIBID Program at a Computer Science Teacher \\ Training Program: Computer Science Teaching in the Public School
}

Pauleany Simões de Morais

Instituto Federal de Educação, Ciência e Tecnologia do Rio Grande do Norte - IFRN

Instituto Federal da Bahia - IFBA

pauleany.morais@ifrn.br

pauleanysm@gmail.com

\author{
Marlo Souza \\ Instituto de Matemática e Estatística \\ Universidade Federal da Bahia - UFBA \\ msouzal@ufba.br
}

\begin{abstract}
Resumo
Este trabalho versa sobre as especificidades da política de formação inicial de professores no Curso de Licenciatura em Informática no Instituto Federal de Educação, Ciência e Tecnologia do Rio Grande do Norte. Trata das ações operacionalizadas no Programa Institucional de Bolsas de Iniciação à Docência (PIBID) em 03 (três) escolas na região da Zona Norte de Natal/RN. O presente estudo foi realizado por meio de revisão de literatura sobre formação docente e Ensino da Computação, bem como de uma pesquisa-ação nas escolas-campo parceiras do projeto, realizada entre os anos de 2012 e 2015, e da análise teórico-metodológica sistematizada ao longo das ações. Observa-se que o PIBID é uma significativa oportunidade de constituição dos saberes docentes necessários à prática didático-pedagógica no contexto escolar, particularmente no que concerne ao Ensino de Computação nas Escolas Públicas. Apesar da vivência de dificuldades acerca das condições materiais nas instituições públicas vinculadas ao Programa, conseguiu-se promover a inclusão de Tecnologia Educacional e difusão do pensamento computacional na Escola. As atividades desenvolvidas evidenciam a necessidade da interação entre a Instituição de Ensino Superior e as Escolas de Educação Básica na constituição da formação inicial de Licenciandos em Informática e promoção de disseminação do pensamento computacional no contexto escolar.
\end{abstract}

Palavras-Chave: Formação inicial docente; PIBID; Ensino de Computação.

\begin{abstract}
This work deals with the specificities of the initial teacher training policy in the Degree in Informatics at the Instituto Federal de Educação, Ciência e Tecnologia do Rio Grande do Norte. It deals with the actions implemented in the Institutional Program for Teaching Initiation Scholarships (PIBID) in 03 (three) schools in the North Zone of Natal $/ R N$. The present study was carried out through a literature review on Initial Teacher Training and Computer Science Education, as well as an action research carried out between the years 2012 and 2015 in the partner schools of the project, as well as a theoretical-methodological analysis of the developed the actions. We notice that the referred program is a significant opportunity for the constitution of the teaching knowledge necessary for didacticpedagogical practice in the school context, particularly with regard to the Computer Science Teaching in the context of Brazilian Public Schools. Despite the difficulties experienced regarding the material conditions of the public institutions in which our actions were developed, it was possible to promote the inclusion of Educational Technology and the diffusion of Computational Thinking in the schools. The activities developed in this experience show the necessity of the interaction between Higher Education Institutions and Basic Education Schools in the constitution of the initial teaching training for Computer Science Teacher and the dissemination of Computational Thinking in the school context.
\end{abstract}

Keywords: Initial teacher formation; PIBID; Computer teaching.

Cite as: Morais, P. S. de, \& Souza, M. (2021). An experience in Coordinating the PIBID Program at a Computer Science Teacher Training Program: Computer Science Teaching in the Public School (Experiência na Coordenação de Área do PIBID da Licenciatura em Informática: Ensino de Computação na Escola Pública). Brazilian Journal of Computers in Education (Revista Brasileira de Informática na Educação RBIE), 29, 117-132. DOI: 10.5753/RBIE.2021.29.0.117 


\section{Introdução}

A formação de professores vem sendo ao longo dos anos pauta de debates em ambientes acadêmicos e na realidade das instituições educacionais, particularmente no Ensino Público, com a promulgação de legislações específicas. Nesse sentido, nos anos 2000, instituiu-se o Programa Institucional de Bolsa de Iniciação à Docência (PIBID) pela Portaria n. 72, de 9 de abril de 2010, que fornece bolsas a estudantes das licenciaturas visando oportunizar a estes a vivência da docência.

A finalidade do PIBID é fomentar a iniciação à docência de discentes da licenciatura plena das instituições de ensino superior federais, estaduais, municipais e comunitárias sem fins lucrativos, com o intuito de estimular a formação dos educadores, valorizar o magistério e colaborar para a elevação da qualidade da educação básica. No ano de 2013, o Programa foi vinculado à LDB 9.394/96, em que as ações vinculam o Ensino Superior à Educação Básica, de acordo com a portaria $\mathrm{n}^{\circ}$ 096, de 18 de julho de 2013, anexo I, art. $2^{\circ}$ que assegura os objetivos do programa (Brasil, 2013).

Neste trabalho, analisa-se uma concepção de formação inicial de professores e discute-se a realidade específica de um curso de Licenciatura em Informática numa Instituição de Ensino Superior na Zona Norte da cidade de Natal/RN, região Nordeste do Brasil, através de sua materialização em ações do PIBID realizadas no contexto da Escola Pública. De maneira específica, desenvolvem-se estudos teóricos sobre a formação inicial de professores, bem como análise de ações na práxis educativa no que concerne ao Ensino da Computação em uma realidade específica. Com esse estudo, mostrou-se a relevância do programa para a formação inicial dos licenciandos na constituição dos saberes docentes necessários à atuação profissional e contribuições significativas à realidade da Escola Pública com mudanças desde a sua estrutura física, bem como inclusão de atividades didático-pedagógicas voltados ao Ensino de Computação.

Observou-se, de um modo geral, que a formação inicial de professores, realizada principalmente nas licenciaturas, tem um papel significativo na constituição dos saberes docentes que acompanharão os licenciandos no decorrer do seu desenvolvimento profissional. Por isso, o PIBID tem um papel essencial na compreensão da realidade escolar desde o início da formação docente, bem como mobiliza novas práticas didático-pedagógicas relacionadas à disseminação do pensamento computacional. Por isso, neste trabalho buscou-se sistematizar um quadro demonstrativo, apresentado na Seção 5, com uma reflexão teórica-metodológica que articula a constituição dos saberes docentes e as práticas didático-pedagógicas vivenciadas no PIBID.

Na revisão de literatura realizada neste trabalho, se faz necessário refletir sobre a relevância da formação inicial de professores, abordando a concepção de autores que recebem destaque tais como: Tardif (2012), Imbernón (2006), Valliant e Garcia (2012), Ramalho, Gauthier e Nuñez (2003), dentre outros. De maneira específica, analisam-se estratégias para desenvolvimento do pensamento computacional destacado por Wing (2006). Diante dos estudos abordados, tem-se como categorias norteadoras formação inicial de professores, desenvolvimento do pensamento computacional e Ensino da Computação.

Este trabalho está estruturado da seguinte forma: na segunda seção trata-se das perspectivas de formação docente, bem como as necessidades de processos formativos necessários ao ensino de computação; na terceira seção, discutem-se os encaminhamentos metodológicos que embasaram o estudo apresentado; na quarta seção, apresenta-se o relato de experiência da atuação na Coordenação de área do PIBID com foco na prática educacional desenvolvida em escolas públicas que foram lócus de atuação dos bolsistas vinculados ao Programa; na sequência, destacam-se as repercussões das ações do PIBID na constituição dos saberes docentes ao longo da atuação dos bolsistas; na última seção foi resgatada a relevância das atividades desenvolvidas 
no PIBID, diante dos estudos desenvolvidos, bem como as possibilidades de disseminação do pensamento computacional, além da formação inicial de licenciandos.

\section{Perspectiva de Formação Docente ao Ensino de Computação}

A Formação Profissional Docente representa um processo em que o sujeito constrói um conhecimento pedagógico especializado, vivenciado no espaço das instituições formadoras ou orientado por estas. Os estudos sobre a formação profissional mostram que o exercício profissional na realidade social deve considerar a relevância do processo ação-reflexão-ação (Ramalho, Gauthier, Nuñez, 2003). Assim, a formação centrada na Escola é mais que uma simples mudança de lugar da formação (Tardif, 2012). A Escola, sendo considerada como lugar de formação, permite vivenciar as contradições da própria atuação profissional, bem como compreender a importância da fundamentação teórico-prática da docência.

Quando se trata da prática docente, deve-se preparar um profissional considerando sua dimensão científica, técnica, tecnológica, pedagógica, cultural e humana. Ademais, esse profissional deve refletir constantemente sobre o seu fazer, pesquisando-o nos próprios contextos nos quais ocorre (Pimenta \& Ghedin, 2005). Nessa perspectiva, pode-se dizer que a formação centrada na Escola envolve todas as condições necessárias para desenvolver os programas de formação, pois é o campo empírico que por excelência proporciona respostas às demandas da própria Escola, como a elevação da qualidade do ensino e da aprendizagem em sala de aula, bem como deve ser o campo empírico para responder às necessidades das instituições superiores (Imbernón, 2006). Assim, quando se fala de formação centrada na Escola, entende-se que a instituição escolar se configura em lugar de formação prioritária, diante de outras ações formativas.

Nota-se que a constituição da prática docente é um exercício constante. No entanto, a formação inicial constituída na graduação apresenta-se como um momento significativo para a construção da identidade docente e as possíveis compreensões para o desenvolvimento profissional da docência dos licenciandos. É imprescindível, portanto, considerar que "a formação inicial do professor de níveis iniciais é o primeiro ponto de acesso ao desenvolvimento profissional contínuo" (Vaillant \& Garcia, 2012, p. 63). Por isso, defende-se neste trabalho uma formação inicial vivenciada em Programas de Iniciação à Docência, que possa contribuir com a constituição dos saberes docentes em seus diversos aspectos, ou seja, considerando a formação profissional, disciplinar, curricular e experiencial (Tardif, 2012).

Tardif (2012, p. 54) define o significado do saber docente como "saber plural, formado de diversos saberes provenientes das instituições de formação, da formação profissional, dos currículos e da prática cotidiana". Assim, é essencial na construção dos saberes docentes uma formação qualificada em instituições educacionais, que mobilizem conhecimentos aos atos de ensinar. $\mathrm{O}$ autor delimita uma caracterização construída a partir dos próprios docentes e dos saberes que eles utilizam, de forma afetiva, em sua prática: saberes da formação profissional voltados às ciências da educação (teorias e métodos); saberes disciplinares (referentes aos saberes em cada área do conhecimento); saberes curriculares (selecionados e categorizados pelas instituições escolares); e saberes experienciais (constituídos em sua essência na base do trabalho cotidiano).

A formação docente para atuação profissional no Ensino da Computação traz a necessidade de refletir sobre as diversas possibilidades de desenvolver o pensamento computacional, ou raciocínio computacional, atrelado aos processos educacionais nos diversos níveis e modalidades da educação. Na discussão sobre pensamento computacional, Wing (2006) apresenta-se de forma pioneira, referindo-se às diversas possibilidades analíticas da computação. Desse modo, o conceito defendido pela autora (idem) relaciona-se com o potencial da computação diante da 
necessidade de desenvolvimento do pensamento computacional que se destina à resolução de problemas, abstração, decomposição, automação, simulação, modelação, pensamento recursivo, sequencial e paralelo. Mostra-se a relevância dos estudos recentes sobre pensamento computacional no que se refere à resolução de problemas do cotidiano, pois estimula o pensamento analítico e o raciocínio dedutivo (Ferreira et. al., 2015; Brackmann, 2017; Conforto, Cavedini, Miranda \& Caetano, 2018).

Em sua tese, Brackmann (2017) apresenta como os quatros pilares necessários ao desenvolvimento do pensamento computacional as seguintes habilidades: a decomposição, o reconhecimento de padrões, a abstração e os algoritmos. A primeira refere-se à identificação de um problema, dividi-lo em unidades menores e mais viáveis de se gerenciar, sendo reconhecido como o processo de Decomposição. Na sequência, cada uma dessas sequências menores seria percebida individualmente com maior intensidade, reduzindo assim a complexidade no momento de resolvê-los. Ao final, as unidades solucionadas poderiam ser novamente agrupadas, processo esse denominado de Composição. Nesse contexto, pode-se identificar elementos e/ou características semelhantes solucionadas em outras situações-problemas por meio do Reconhecimento de Padrões. A habilidade denominada Abstração significa atentar-se aos detalhes significativos, em que as informações irrelevantes são desconsideradas e os Algoritmos representam passos ou regras simples que conduziram para solucionar os subproblemas identificados.

O conceito de 'pensamento computacional' vem ganhando espaço e sua importância vem sendo reconhecida em vários projetos educacionais desenvolvidos no mundo, evidenciado pelos recentes projetos em torno do mesmo. De acordo com Carvalho et al. (2013), se destacam ações recentes desenvolvidas em escolas do Ensino Médio do Estado do Alabama nos Estados Unidos (EUA), bem como iniciativas de um projeto multidisciplinar entre professores de computação e língua inglesa. No Brasil, recebem ênfase iniciativas em diversas partes do país apresentadas em eventos acadêmico-científicos apoiados pela Sociedade Brasileira de Computação dos quais se destacam o Workshop Informática na Escola e o Simpósio Brasileiro de Informática na Educação (Zanini \& Raabe, 2012).

Por outro lado, o estudo apresentado por Bombasar et al. (2015) sobre o Ensino de Computação procura evidenciar as principais ferramentas utilizadas para desenvolvimento do pensamento computacional diante de uma revisão de literatura nos diversos meios científicos entre os anos de 2006 a 2015. Nesse estudo, os autores (2015) apontam um acentuado interesse da comunidade científica pelo ensino do pensamento computacional na Educação Básica com ênfase em ferramentas que utilizam Linguagens Visuais de Programação, tais como: Scratch, App Inventor, Alice, Scalable Game Design (SGD), AgentSheet e Kodu.

De fato, a importância do desenvolvimento do pensamento computacional na Educação Básica vem sendo enfatizada por autores como Brackmann (2017) e Conforto et al. (2018), assim como defendida pela Sociedade Brasileira de Computação - com o Pensamento Computacional figurando como um eixo estruturante em seus referenciais de formação para a Educação Básica (Raabe, Frango, Ribeiro, Granville, Salgado, Cruz, \& Fortes, 2017). Nesse sentido, Conforto et al. (2018) argumentam que o domínio do pensamento computacional permite a superação do modelo em que os estudantes são postos como consumidores de produtos tecnológicos para um modelo em que a Computação e suas tecnologias podem ser vistas como linguagens com as quais lemos e nos relacionamos com o mundo. Ou seja, desenvolver o pensamento computacional significa desenvolver competências para entender e manipular os signos e estruturas de tais linguagens.

Observa-se que o Ensino de Computação vem sendo repensado ao longo dos anos e exige uma formação docente que permita viabilizar as melhores estratégias de ensino para a disseminação do pensamento computacional, no sentido de conduzir uma aprendizagem 
significativa nos diversos níveis e modalidades de ensino. Diante das discussões acadêmicocientíficas estabelecidas em produções sobre o Ensino de Computação tem-se apresentado a relevância e possíveis modificações que perpassam todas as modalidades de Ensino desde a Educação Básica até o Ensino Superior. Portanto, a formação docente, particularmente, a inicial, torna-se uma possibilidade concreta de melhoria do Ensino de Computação na Escola Pública.

\section{Metodologia}

Este estudo consiste num relato de experiências vividas na coordenação da área Informática no Programa Institucional de Bolsas de Iniciação à Docência (PIBID) em três escolas na região da Zona Norte de Natal/RN nos anos de 2014 e 2015. Diante das reflexões até o momento desencadeadas sobre as particularidades da formação de professores e suas repercussões no Ensino da Computação por meio do desenvolvimento do pensamento computacional, apresentase a possibilidade de contribuir para o delineamento teórico-metodológico de uma investigaçãoação-participativa, que articule estudos e planejamento acadêmico-científicos (produção) com atuação em atividades de ensino-pesquisa-extensão.

Diversos autores reconhecem Kurt Lewin, nos anos de 1940, como aquele que concebeu a investigação-ação. Em 1944, o referido investigador já descrevia o processo de pesquisa-ação indicando um ciclo vital: planejar, agir, descrever e avaliar (Tripp, 2015). Nesse contexto, a atuação PIBID em parceria com o Instituto Federal de Educação, Ciência e Tecnologia do Rio Grande do Norte (IFRN) teve como encaminhamento metodológico a pesquisa-ação, pois propôs o desenvolvimento de ações didático-pedagógicas indicadas em planejamentos, reuniões e orientações para a realização de formações nas escolas. Desse modo, as experiências aqui relatadas constituíram-se de um tipo de investigação social concebida e realizada em estreita associação com uma ação ou proposição para um problema coletivo, no qual investigadores e outros sujeitos participam, interagem, opinam e discutem de modo coletivo, democrático e criticamente no desenvolvimento da investigação.

Para viabilizar esse trabalho, há caminhos teórico-metodológicos que sugerem o uso de alguns procedimentos indispensáveis à coleta e análise dos dados a fim de responder às questões de pesquisa e às de ensino. Dentre os procedimentos de pesquisa utilizados, evidenciam-se: a revisão da literatura, análise documental, notas de campo e realização de formações relacionadas para o Ensino de Computação em busca ao desenvolvimento do pensamento/raciocínio computacional.

As ações didático-pedagógicas relatadas nesse artigo buscaram ampliar as oportunidades educacionais na região em que se localizam as escolas que foram o lócus das ações do PIBID em parceria com o IFRN. Desse modo, as ações aqui relatadas foram desenvolvidas em 03 escolas do Ensino Básico (Fundamental e Médio) localizadas na região da Zona Norte da Cidade de $\mathrm{Natal} / \mathrm{RN}$, região nordeste do Brasil, que serão doravante identificadas como escola 01, 02 e 03.

Vale salientar que a região das escolas foi constituída no final dos anos de 1970 e início dos anos de 1980 devido ao intenso processo de urbanização resultado do êxodo rural vivenciado no Estado do Rio Grande do Norte. Historicamente, essa região recebeu, ao longo dos anos, restrita atenção no que se refere a atendimentos sociais básicos de habitação, saúde, segurança, educação, dentre outros. De acordo com Capistrano, Macêdo, Pinheiro, Costa, \& Silva (2013), a região denominada Zona Norte localiza-se à margem direita do Rio Potengi e passou despercebida diante do processo de desenvolvimento de Natal. Os autores (2013) destacam, ainda, que essa região recebeu pouca atenção com o processo de expansão da cidade até a segunda metade do século $\mathrm{XX}$. 
Ao saber que a realidade social do Rio Grande do Norte, marcada por intensas desigualdades, inclusive com intensas diferenciações entre suas regiões, observa-se que:

A busca de respostas para reduzir as desigualdades que caracterizam o Brasil, e que se aguçam no Nordeste e retratam o Rio Grande do Norte, muitas vezes, culmina com programas assistencialistas que perpetuam os problemas. E no sistema educacional público refletem-se as consequências dessa situação. (Almeida et al., 2006, p. 23)

Ao compreender a realidade educacional mostra-se que a região da Zona Norte de Natal possui 14 escolas estaduais no universo de 54 no município de Natal (Silva \& Barroso, 2010). Nesse caso, realizou-se a inclusão de bolsistas em 03 escolas estaduais nessa região da cidade, a fim de contribuir para a melhoria da qualidade do ensino, entendendo as necessidades sociais e educativas constatadas nessas instituições educativas públicas. Diante disso, as escolas selecionadas possuem o valor do IDEB no ano de 2011 de 2,5 para a Escola 01; 3,0 para a Escola 02 e 2,3 para a Escola 3. Ao comparar os índices dessas escolas com outras do país, observa-se que as mesmas estão abaixo da média nacional. Portanto, acreditamos naquele momento que a atuação dos bolsistas por meio do PIBID poderia contribuir para a melhoria da qualidade do ensino, auxiliando em concomitância com outros Programas do Ministério da Educação para o alcance da elevação dos índices educativos das escolas atendidas.

Nesse contexto, participaram de tais ações 30 (trinta) estudantes do curso de Licenciatura em Informática, divididos em grupos de 10 bolsistas em cada escola-campo. Além dos estudantes, participaram desse projeto 3 (três) professores supervisores - um em cada escola-campo - e 1 (um) coordenador de área no IFRN. Visando explorar a interdisciplinaridade na formação inicial do professor de computação e dada a realidade, na época, da ausência de professores de computação licenciados nas redes municipais e estaduais de ensino, foram escolhidos como supervisores professores de áreas distintas, atuando na área de Pedagogia, Língua Portuguesa e Sociologia.

A primeira ação conduzida foi a elaboração de um diagnóstico informativo da realidade de cada escola, a fim de compreender o contexto, a organização escolar, assim como, suas necessidades estruturais e de formação na área de informática. Com base nesse diagnóstico, iniciou-se o planejamento das ações formativas a serem realizadas nas escolas-campo. A produção dos diagnósticos permitiu a compreensão da realidade escolar, bem como a estruturação, organização e revitalização dos laboratórios de Informática de todas as escolas vinculadas ao PIBID. Diante da permissão dos gestores das escolas realizou-se a manutenção nos computadores, bem como alteração no layout do laboratório para uma melhor mobilidade e manutenção no roteador sem fio (quando necessário).

Durante todo o andamento do projeto, foram realizadas reuniões periódicas no IFRN e nas escolas, com periodicidade no mínimo semanal, visando a socialização do andamento das formações, os problemas encontrados e a produção de material didático e artigos, além de auxiliar os alunos nas ações planejadas.

No processo de planejamento das ações, de acordo com o contexto de cada escola, foi definida a realização de formações para o perfil da comunidade escolar. Foram realizadas as seguintes formações: Informática básica, Manutenção básica de computadores, Linux educacional, Programação com Scratch e Computação desplugada. Na Escola 01, recebeu destaque as formações destinadas a Introdução à informática e a Computação desplugada. A Escola 02 destacou-se pelo desenvolvimento das formações de Computação desplugada no ensino fundamental e ações com o uso do Scratch, enquanto, na Escola 03, os bolsistas direcionaram suas ações as formações de Introdução a informática, bem como Programação com uso da linguagem Scratch. 
No contato inicial com o campo empírico, foi realizado o registro diante dos diagnósticos realizados por meio de notas de campo (observação), com o intuito de compreender o processo organizativo da instituição educativa no qual o estudo foi materializado. Entendem-se notas de campo como "o relato escrito daquilo que o investigador ouve, vê, experiencia e pensa no decurso da recolha e refletindo sobre os dados de um estudo qualitativo" (Bogdan \& Biklen, 1994, p. 150). Bogdan e Biklen (1994) ainda apresentam possibilidades de organizar as notas de campo, uma vez que podem ser descritivas ou reflexivas. A primeira preocupa-se em "captar uma imagem por palavras do local, pessoas, ações e conversas observadas" (Bogdan \& Biklen, 1994, p. 152), enquanto a segunda se refere à "parte que aprende mais do ponto de vista do observador, as suas ideias e preocupações" (Bogdan \& Biklen, 1994, p. 152). As notas de campo são necessárias para a melhor compreensão da prática educacional desenvolvida, uma vez que podem revelar ou desvendar o que não aparece de maneira evidente nos discursos, tampouco em registros escritos diagnósticos e relatórios produzidos da escola. Nesse caso, elaborou-se um roteiro para a organização de registros com destaque aos aspectos que necessitam ser observados em notas presentes na realidade escolar.

Além disso, realizaram-se, concomitantemente, estudos de literatura específica para compreensão do Ensino de Computação na Escola Pública. Esses estudos possibilitaram a análise do conteúdo coletado nas escolas, bem como a fundamentação para produção de relatórios avaliativos das práticas vivenciadas na Escola Pública. No tratamento dos dados coletados nas experiências vividas nas escolas, buscou-se uma análise de cunho qualitativo, considerando os referenciais teórico-metodológicos de formação de professores e ensino da computação. Por consequência, foi sistematizado, na Seção 5, em forma de quadro demonstrativo o transcurso da constituição dos saberes docentes na vivência dessas ações didáticas, metodológicas e experiências realizadas no PIBID, apresentadas na Seção 4 abaixo. O quadro possui significativa contribuição para auxiliar ações de formação inicial de professores, sendo compreendido como uma sistematização de estudo que conduza as práxis educativas ao ensino de computação com possibilidades de articular e ampliar a compreensão da trajetória acadêmica formativa do Licenciando e suas vivências na concretude real da escola. Além disso, os estudantes foram estimulados a elaborar e submeter artigos para veículos na área de computação e educação e participar de eventos acadêmicos-científicos da área.

\section{Relato de Experiência da atuação na Coordenação de área do PIBID: fundamentos de estudos em Ensino de Computação e a práxis educativa}

Inicialmente, o PIBID instalado na Licenciatura em Informática foi viabilizado com a sistematização de reuniões iniciadas no ano de 2012 entre bolsistas, supervisores e coordenadores de área. Essas reuniões tiveram como objetivo acompanhar ações de iniciação da prática docente em suas diversas dimensões - compreensão da realidade escolar, estudos sistemáticos, planejamentos de ensino e atividades de culminância voltada ao Ensino de Computação. Havia 30 bolsistas vinculados ao Programa divididos entre as três escolas públicas estaduais da Zona Norte de Natal.

Nas reuniões iniciais, houve a preocupação de seleção da literatura voltada à formação de professores e as possibilidades de ensino de computação que embasasse o planejamento e a prática didático-pedagógica dos futuros docentes. Como referencial teórico na compreensão desse estudo, elenca-se uma revisão de literatura sobre formação docente que contribua a uma prática de ensino qualificada, além de estudos sobre a formação docente necessária às especificidades do Ensino de Computação com ênfase no desenvolvimento do pensamento/raciocínio computacional apresentados, principalmente, no Congresso da Sociedade Brasileira de Computação (CSBC) e no Simpósio Brasileiro de Informática na Educação (SBIE). 
No transcurso das reuniões, utilizou-se a metodologia de seminários para o desenvolvimento dos estudos junto aos alunos bolsistas sobre ensino de computação. Além disso, foi realizado um levantamento da realidade escolar nas dimensões da gestão escolar (administrativa e pedagógica), bem como da estrutura dos laboratórios (software, hardware e qualidade das máquinas). Nas reuniões com a coordenação de área, observou-se a necessidade de realizar projetos específicos nas escolas sobre Introdução à Informática e iniciou-se a produção de materiais orientadores da prática educativa.

A problemática da ausência do profissional específico da área de Informática nas escolas públicas ainda compromete as ações mais efetivas para acompanhamento das formações. Essa problemática exige a presença mais intensa dos Coordenadores de Área no planejamento e na implementação das ações para garantir a inclusão da Tecnologia Educacional na formação dos estudantes ou mesmo dos professores. Mesmo com todas as dificuldades, acredita-se que a inserção dos licenciados nas escolas promove um significativo contato do educando em seu próprio campo de conhecimento (Gaspar, Ribeiro \& Silva, 2013). Nesse caso, eles possuem função ativa enquanto sujeitos da aprendizagem com oportunidades de sistematizar habilidades de docência e de refletir sobre a constituição de sua profissionalidade.

As reuniões vivenciadas nas escolas e na instituição de formação tiveram o intuito de promover o diálogo e a cooperação, necessários à formação universitária, pois permitiram aos licenciandos e à Coordenação de área desenvolverem processos de reflexão e de (re)construção do próprio conhecimento. Para Imbernón (2006), esse processo auxilia na construção da identidade docente e da tomada de consciência do papel social por parte dos licenciandos. Desse modo, induz o pensamento reflexivo necessário à constituição da identidade profissional que impulsiona a indagação, a busca e o questionamento de maneira contínua de sua própria prática educativa.

Em momento inicial, houve a oportunidade de promover cursos de inclusão digital (Introdução a Informática) tanto para os alunos das escolas 01 e 03 quanto para a comunidade em torno. Tais cursos objetivam prover o acesso à informática aos sujeitos da comunidade escolar e tirá-los da exclusão digital, ou analfabetismo digital - expressão surgida nos últimos anos da década passada para definir as pessoas que não possuem familiaridade com o mundo da informática, como afirma Pretto, Souza e Rocha (2011). Note que, em virtude da intensa exigência de domínio dos meios de comunicação e informação, como o computador, na sociedade da informação, atividades de inclusão digital nessas comunidades são também ferramentas de inclusão social das mesmas, visando integrá-los a vida da sociedade contemporânea e melhorando sua relação com o mundo do trabalho, os negócios ou mesmo atividades de lazer e integrativas por meio das redes sociais. Como um resultado colateral dessas atividades, desenvolveu-se também, juntamente com as escolas envolvidas, material didático produzido pelos bolsistas para condução dos cursos de Inclusão Digital, inclusive com participação de idosos da própria comunidade.

Nos meses finais de 2014 e iniciais de 2015, foram realizadas reuniões periódicas entre os coordenadores de área, os alunos bolsistas e os supervisores, a fim de ter um acompanhamento dos trabalhos planejados e os realizados nas escolas. No ano de 2014, as atividades foram concentradas no planejamento e na execução de cursos de Informática Básica. Os alunos bolsistas também se envolveram na manutenção dos computadores dos laboratórios das escolas ao firmar parceria com o Projeto de Extensão vinculado ao Curso Técnico em Manutenção de Computadores do IFRN. Tais ações foram necessárias, dada as intensas problemáticas para utilização das máquinas no desenvolvimento das ações didático-pedagógicas do PIBID. Além disso, os bolsistas efetuaram alterações na disposição dos computadores, permitindo uma melhor mobilidade. 
Vale evidenciar que no ano de 2015, o planejamento de trabalho dos bolsistas foi direcionado a formações voltadas ao desenvolvimento do pensamento computacional (Wing, 2006). Elaborouse um planejamento com cursos de formação em raciocínio lógico, computação desplugada ${ }^{1} \mathrm{e}$ Scratch $^{2}$ vivenciados nas três realidades escolares. Procurou-se trabalhar tais conhecimentos de maneira lúdica, com uso de jogos e exercícios contextualizados. O objetivo foi estabelecer o contato dos alunos das escolas públicas com a lógica do pensamento computacional, desenvolvendo a criatividade na perspectiva de resolução de problemas, bem como estabelecer um vínculo mais próximo com o computador, não apenas como um operador da máquina.

Nos anos de 2016 e 2017, foram ainda publicados alguns resultados desse projeto em alguns dos principais eventos do país. Considera-se a produção científica do grupo uma etapa de culminância para divulgação dos trabalhos desenvolvidos, bem como movimento de reflexão sobre a própria prática desenvolvida de acordo com os estudos sistematizados ao longo do processo de formação à docência, além de articulação com pesquisadores de outros Estados da Federação e suas pesquisas. O presente trabalho caracteriza-se, então, como uma sistematização das experiências relatadas de forma pontual nessas publicações e das reflexões conceituais provenientes dos resultados por elas descritos e das discussões que delas advieram.

Ao longo da atuação empreendida na escola, aperfeiçoaram-se as ações no campo do desenvolvimento do pensamento computacional de acordo com os estudos de Wing (2006), na tentativa de construir outros espaços para vivência da Informática e do Ensino da Computação. Atua-se nas escolas com formações no campo da iniciação a programação, desenvolvendo ações referentes a computação desplugada com atividades de raciocínio lógico, bem como robótica e jogos educacionais.

A Computação Desplugada consiste em ensinar fundamentos da computação sem o uso do computador. O objetivo era promover ações baseadas na literatura de Bell et al. (2011) que propõe atividades lúdicas para o Ensino de Computação baseadas em conceitos matemáticos, sem a complexidade de detalhes técnicos. Dessa forma, a técnica pode ser aplicada para pessoas de todas as idades. Um dos objetivos de tal abordagem é eliminar as barreiras tecnológicas sobre o que é computação (Ferreira et. al., 2015), o que a torna uma abordagem viável para o Ensino de Computação nas Escolas Públicas, diante das dificuldades encontradas para a manutenção das máquinas nesses espaços - em que usualmente há deficiência de pessoal com conhecimento técnico necessário para fazê-lo. Além disso, tal abordagem permite ainda ao aluno o contato lúdico com a lógica computacional (Ferreira et al., 2015), facilitando sua aprendizagem. De fato, recentemente, relatos de experiência de projetos de PIBID desenvolvidos na Escola Pública como os de Sarmento, Farias, \& Santos (2017) ou o de Marinho, de Morais, de Souza \& do Nascimento (2018) - apontam para a importância do uso de estratégias de Computação Desplugada para superar limitações técnicas e políticas para a introdução do Ensino de Computação na Rede Pública de Educação Básica.

Nas ações promovidas pelo PIBID, convidou-se os professores que atuam na Licenciatura a prestigiar algumas vivências em uma escola-campo com o intuito de ampliar a compreensão sobre a formação inicial necessária aos licenciandos. Desse modo, as ações vivenciadas no PIBID também tiveram impactos na realidade da Instituição de formação dos bolsistas. Os professores começaram a incorporar a suas aulas, metodologias com a Computação Desplugada. Por consequência, foi promovida uma vivência didático-pedagógica utilizando a Computação Desplugada entre discentes do Curso Técnico em Informática e os Licenciandos em Informática do IFRN com a participação da Coordenação de Área. A vivência tinha como objetivo aprender os conceitos fundamentais da disciplina de Banco de Dados voltados ao desenvolvimento da

1 http://csunplugged.org/

2 http://scratch.mit.edu/ 
abstração e do raciocínio lógico (Martinhado et. al. 2017). Interessante observar como as ações do PIBID vão sendo internalizadas em ações da própria práxis educacional no Curso da Licenciatura em Informática no IFRN.

De uma maneira geral, a partir das ações promovidas pelo PIBID na escola-campo, observouse uma significativa valorização dos laboratórios de informática como espaço de formação para comunidade interna e externa. O planejamento das ações junto à escola, permitiu a vivência cada vez mais intensa de intervenção com práticas educacionais mais contextualizadas. Mostra-se uma repercussão ampla em todo o Curso de Licenciatura em Informática, pois o Programa despertou o interesse dos docentes, vinculando ações na própria formação em diversas disciplinas desse Curso. Nesse contexto, defende-se um movimento articulado de formação inicial dos bolsistas em diversas outras disciplinas do Curso que possibilitaram mobilizar os saberes experienciais, disciplinares, curriculares e profissionais.

Diante das especificidades do Ensino de Computação, as ações promovidas puderam, mesmo com dificuldades, promover ações educativas diferenciadas nas Escolas Públicas. Observou-se que foi possível constituir um ciclo de formação que promovesse na Escola a descrição-execuçãoreflexão-depuração-descrição com o intuito do aluno construir seu próprio conhecimento (Valente, 2008).

A Ciência da Computação caracteriza-se por ser uma área do conhecimento com natureza de caráter universal, auxiliando culminância de processos didático-pedagógicos interdisciplinares (Ferreira, 2015). Nesse caso, o Ensino da computação na Escola Pública pode promover ações educativas qualificadas de desenvolvimento do pensamento computacional e inclusão da Tecnologia Educacional no sentido de otimizar a resolução de problemas nas diversas áreas do conhecimento, bem como problemáticas do cotidiano.

\section{Repercussões das práxis educacionais vivenciadas no PIBID: possibilidades de constituição dos saberes docentes}

A vivência na coordenação do PIBID permitiu a observação mais próxima das problemáticas, particularmente das Escolas Públicas Estaduais e a compreensão na realidade escolar a relevância do Licenciado em Informática para impulsionar o acesso à Tecnologia Educacional e ao Ensino de Computação. A fim de concretizar essas demandas às Secretarias e conclamar apoio às ações, a Coordenação de Área do PIBID, juntamente com os professores da Licenciatura, elaboraram um documento que foi entregue aos Secretários de Educação Estadual e Municipal em mãos.

Nesse projeto, procurou-se em toda a atuação induzir os licenciandos à relevância da ação prática de formação desenvolvida junto à comunidade, em que o princípio da interação seja resgatado em conhecimentos fundamentais à atuação profissional futura e as ações de cunho metodológico que podem auxiliar o desencadear do Planejamento realizado junto à escola. Para Vaillant e Garcia (2012, p. 75), "as experiências práticas de ensino representam uma ocasião privilegiada para pesquisar o processo de aprender a ensinar”. Por consequência, apresentam-se como uma significativa oportunidade de vivenciar experiências práticas de docência em um contexto de formação inicial presente de maneira real desde o início da graduação. Além disso, a experiência com vivências práticas de docência desenvolve no aluno o desejo de transformação social de uma dada realidade escolar que clama por processos de inclusão digital, bem como o desenvolvimento do pensamento computacional na perspectiva de resolução de problemas do cotidiano.

Desse modo, sistematizou-se um quadro com as indicações dos saberes docentes, instituídos ao longo da gestão na Coordenação do Programa, enfatizando o Ensino de Computação em situações reais de aprendizagem. A elaboração do quadro foi baseada nos estudos de Tardif 
(2012), no que se refere à constituição dos saberes docentes nas dimensões da formação profissional, disciplinares, curriculares e experienciais.

Quadro 1: Organização das ações desenvolvidas no PIBID - Ensino de Computação a partir dos saberes docentes constituídos.

\begin{tabular}{|c|c|c|c|c|}
\hline SABERES & $\begin{array}{l}\text { Formação } \\
\text { Profissional }\end{array}$ & Disciplinares & Curriculares & Experienciais \\
\hline \multirow{5}{*}{$\begin{array}{l}\text { Ações do } \\
\text { PIBID } \\
\text { (Contribuições } \\
\text { à formação } \\
\text { docente) }\end{array}$} & $\begin{array}{l}\text { Estudos das } \\
\text { disciplinas } \\
\text { didático- } \\
\text { pedagógicas; }\end{array}$ & $\begin{array}{l}\text { Resgatar estudos } \\
\text { didático- } \\
\text { pedagógicos } \\
\text { específicos } \\
\text { ciência da } \\
\text { computação; }\end{array}$ & \begin{tabular}{lr}
\multicolumn{2}{l}{ Resgatar estudos } \\
das disciplinas \\
vivenciadas no \\
Curso da \\
Licenciatura em \\
Informática;
\end{tabular} & $\begin{array}{ll}\text { Adequar } & \text { o } \\
\text { planejamento } & \text { a } \\
\text { realidade } & \\
\text { escolar; } & \end{array}$ \\
\hline & $\begin{array}{l}\text { Seminários } \\
\text { para discussão } \\
\text { sobre } \\
\text { planejamento } \\
\text { Ensino e } \\
\text { Ensino de } \\
\text { computação; }\end{array}$ & \multirow{4}{*}{$\begin{array}{l}\text { Estudos sobre o } \\
\text { desenvolvimento } \\
\text { do pensamento } \\
\text { computacional, } \\
\text { destinado à } \\
\text { resolução de } \\
\text { problemas, } \\
\text { abstração, } \\
\text { decomposição, } \\
\text { automação, } \\
\text { simulação, } \\
\text { modelação, } \\
\text { pensamento } \\
\text { recursivo, } \\
\text { sequencial e } \\
\text { paralelo. }\end{array}$} & $\begin{array}{lr}\text { Estímulo } & \text { a } \\
\text { projetos } & \text { de } \\
\text { eventos } & \\
\text { científicos } & \text { com } \\
\text { auxílio } & \text { dos } \\
\text { bolsistas } & - \\
\text { Semana } & \text { da } \\
\text { Licenciatura } & \text { em } \\
\text { Informática; } & \end{array}$ & $\begin{array}{l}\text { Manutenção } \\
\text { dos } \\
\text { computadores } \\
\text { para realização } \\
\text { de atividades }\end{array}$ \\
\hline & $\begin{array}{lr}\text { Exigência de } \\
\text { Planejamento } \\
\text { de Ensino para } \\
\text { atuação nas } \\
\text { escolas r } \\
\text { resgate de } \\
\text { estudos } \\
\text { teóricos } \\
\text { metodológicos; }\end{array}$ & & \multirow{3}{*}{$\begin{array}{l}\text { Estabelecimento } \\
\text { da relação dos } \\
\text { conhecimentos } \\
\text { curriculares do } \\
\text { Curso de } \\
\text { Licenciatura e a } \\
\text { realidade social } \\
\text { da escola } \\
\text { pública. }\end{array}$} & $\begin{array}{l}\text { Produção } \\
\text { material } \\
\text { didático } \\
\text { atuação; }\end{array}$ \\
\hline & \multirow{2}{*}{$\begin{array}{l}\text { Planejamento } \\
\text { para realização } \\
\text { de pesquisa- } \\
\text { ação. }\end{array}$} & & & $\begin{array}{l}\text { Formações a } \\
\text { comunidade } \\
\text { escolar } \\
\text { inclusão digital, } \\
\text { softwares } \\
\text { educacionais } \\
\text { (Scratch), } \\
\text { computação } \\
\text { desplugada, } \\
\text { dentre outros; }\end{array}$ \\
\hline & & & & $\begin{array}{l}\text { Enfrentamento } \\
\text { de } \\
\text { problemáticas } \\
\text { relacionadas às } \\
\text { realidades } \\
\text { escolares, por } \\
\text { exemplo, } \\
\text { ausências de }\end{array}$ \\
\hline
\end{tabular}




\begin{tabular}{|l|l|l|l|l|}
\hline & & & & $\begin{array}{l}\text { aulas, } \\
\text { organização dos } \\
\text { laboratórios e } \\
\text { acesso à } \\
\text { internet, dentre } \\
\text { outros. }\end{array}$ \\
\hline
\end{tabular}

Esse quadro evidencia a vivência concreta de práxis educacionais em favor da formação docente da Licenciatura em uma área específica relacionada ao Ensino de Computação. Justificase sua relevância, ao refletir sobre possíveis ações que podem ser desencadeadas para constituir os saberes docentes necessários ao Ensino de Computação. Essas práticas devem articular todo o percurso constituído dentro das disciplinas do Currículo do Curso de Licenciatura, bem como constituídas na realidade escolar com vivências da prática da docência. De maneira mais ampla, tem-se como objetivo no percurso alcançar significativas ações didático-pedagógicas de desenvolvimento do pensamento computacional nas Escolas públicas relacionadas ao estudo. Assim, articulamos movimentos da práxis de ensaio da atuação profissional docente com a mobilização dos saberes imprescindíveis à docência ao longo do processo formativo acadêmico e em atuação no lugar profissional futuro.

Com a experiência na Coordenação, houve uma intensa satisfação na vivência profissional de aprofundar estudos sobre Formação Docente, Tecnologia Educacional e Ensino de Computação para contribuir de maneira mais contextualizada na Licenciatura em Informática. Na perspectiva política da atuação na gestão, observou-se o empenho em induzir ações que mostrassem a relevância do docente em Computação diante das novas demandas sociais, bem como promover a melhoria da qualidade do Ensino na Escola pública, ao ampliar as possibilidades de vivências didático-pedagógicas. Em dimensão afetiva-emocional, junto aos licenciandos, aprendeu-se cotidianamente a valorizar cada vez mais o amor pela docência e obter a retribuição por meio do reconhecimento dos futuros docentes em suas ações, mostrando a nós gestores que a mudança pode ser possível na escola pública.

Foi possível perceber que, juntos, realizamos a diferença naquelas escolas e comunidades a qual atuamos. Particularmente, por muitos de nós envolvidos no PIBID morarmos na região da Zona Norte, localidade tão discriminada com restrita atenção social nos processos de expansão de nossa cidade (Capistrano et al., 2013), a percepção de tais impactos foi potente motivador para a continuidade das ações desenvolvidas. Melhor dizendo, um objetivo amplo de todo o processo de atuação do PIBID foi formar um profissional comprometido com a sociedade, sujeitos que promovam ação e reflexão em seu próprio contexto social com atuação transformadora das relações segregadas (Freire, 2006). Mostrou-se que as pessoas moradoras da região podem modificar sua própria realidade social com uma formação qualificada e, posteriormente, atuar nas proximidades diante do desejo de modificar um dado contexto.

\section{Conclusões}

De tudo que foi exposto das ações desencadeadas no Programa, houve a indução de estudos e de disseminação do pensamento computacional, além da formação inicial de licenciandos. Ademais, almejou-se contribuir com o processo de ensino-aprendizagem do Curso de Licenciatura em Informática do IFRN, no sentido de favorecer o processo de formação docente, de conscientização política de professores e de alunos cidadãos. Espera-se que, em âmbito da esfera estadual, sejam oferecidas melhores condições para atuação dos alunos nas escolas inseridas no Projeto, pois vivenciam-se intensas dificuldades no que concerne à sistematização nas escolas dos cursos na área de informática com quantidade e qualidade restrita de computadores. 
Nesse caso, precisa-se de um intercâmbio de informações entre os articuladores do PIBID na CAPES e as Secretarias de Educação Estaduais e Municipais, pois a atuação dos estudantes encontra-se, muitas vezes, comprometida devido às dificuldades existentes na manutenção dos computadores, internet de qualidade, bem como na existência de softwares fundamentais para o trabalho. Ainda, uma dificuldade reside na ausência do profissional licenciado na Escola, com já foi mencionado anteriormente neste trabalho, a fim de organizar e integrar tais espaços formativos nas atividades pedagógicas das escolas.

Durante todo processo de participação na Coordenação de Área, percebeu-se a intensa relevância do Programa para a vivência dos pilares que compõem o Ensino Superior por meio da indissociabilidade entre ensino, pesquisa e extensão como princípio norteador das formações universitárias (Fernandes \& Mendonça, 2015). O Programa é uma valiosa oportunidade de formação não só à docência, mas também à produção material da vida por meio das ações sistematizadas de transformação social na realidade das escolas-campo. Nessa perspectiva, as ações realizadas durante a gestão na Coordenação foram imersas em movimentos articulados de formação docente, no sentido de alcançar esse princípio indutor (tríade ensino-pesquisa-extensão) do Ensino Superior, bem como de promoção de mudanças no contexto escolar, estimulando um processo de inclusão de Tecnologia Educacional com foco no Ensino de Computação.

A constituição dos saberes docentes foi meta constante na atuação do PIBID em toda a trajetória dos anos de 2012 a 2016. Procurou-se, além disso, instituir mudanças qualitativas nas atividades de ensino das escolas em que houve a intervenção pedagógica. Apesar das diversas dificuldades, observa-se que a formação inicial de professores, realizada nas licenciaturas, tem um papel significativo na constituição dos saberes docentes que acompanharão os licenciandos no decorrer do seu desenvolvimento profissional. Apresentam-se, nessa formação, oportunidades essenciais para conectar saberes que mobilizem o conhecimento em suas diversas dimensões e possibilidades de articular teoria e prática na atividade docente.

Por fim, diante da formação inicial docente desencadeada no PIBID, pode-se destacar a relevância da elaboração de uma significativa reflexão em forma de quadro demonstrativo que expõe a busca da constituição dos saberes docentes nas ações vividas nas escolas-campo, bem como na própria Instituição do Curso de Graduação. A organização das ações desenvolvidas no PIBID de maneira demonstrativa pode auxiliar a formação inicial docente por meio da identificação das ações entre a formação oferecida nas Universidades e nos Institutos Federais por meio da Licenciatura em Informática ou em Computação e as vivências que precisam ser articuladas nas escolas públicas, como lócus de atuação futura.

\section{Referências}

Alcaide, V., Elena, D., García, C. M. (2012). Ensinando a ensinar: as quatro etapas de uma aprendizagem. Curitiba: Editora UTFPR. [GS Search]

Almeida, M. D. et. al. (2006). Ensino médio noturno no Rio Grande do Norte: democratização e diversidade. Secretaria de Educação Básica. Disponível em: http://portal.mec.gov.br/component/docman/?task=doc_download\&gid=7612\&Itemid.

Bell, T., Witten; I. H., Fellows, M. (2011). Computer Science Unplugged: ensinando ciência da computação sem o uso do computador (L. P. Barreto, Trad). Disponível em: https://classic.csunplugged.org/wp-content/uploads/2014/12/CSUnpluggedTeachersportuguese-brazil-feb-2011.pdf [GS Search] 
Bogdan, R. C.; Biklen, S. K. (1994). Investigação qualitativa em educação: uma introdução à teoria e aos métodos (M. J. Alvarez, S. B. dos Santos \& T. M. Baptista, Trad.). Porto: Porto Editora. [GS Search]

Bombasar, J., Raabe, A., Miranda, E. M. de \& Santiago, R. (2015). Ferramentas para o ensinoaprendizagem do pensamento computacional: onde está Alan Turing? In: S. C. C. S. Pinto \& D. D. M. C. Matos (Eds.). Brazilian Symposium on Computers in Education. Porto Alegre: Sociedade Brasileira de Computação. doi: 10.5753/cbie.sbie.2015.81 [GS Search]

Brackmann, C. P. (2017). Desenvolvimento do pensamento computacional através de atividades desplugadas na educação básica. [Tese de Doutorado, Universidade Federal do Rio Grande do Sul]. Repositório Digital da Universidade Federal do Rio Grande do Sul. Disponível em: https://www.lume.ufrgs.br/handle/10183/172208. [GS Search]

Brasil, Senado Federal. (1996). Lei de Diretrizes e Bases da Educação Nacional: no 9394/96. Brasília. [GS Search]

Brasil, Ministério da Educação, Conselho Nacional de Educação. (2009). Decreto Presidencial n. 6.755 , de 29 de janeiro de 2009. [GS Search]

Brasil, Ministério da Educação, Coordenação de Aperfeiçoamento de Pessoal de Nível Superior. (2010). Portaria n. 72, de 9 de abril de 2010. Disponível em: http://antigo.capes.gov.br/images/stories/download/legislacao/Portaria72 Pibid 090410.pdf

Brasil. Ministério da Educação, Coordenação se Aperfeiçoamento de Pessoal de Nível Superior. (2013). Portaria No 096, de 18 de Julho de 2013. Disponível em: https://www.in.gov.br/materia/-/asset_publisher/Kujrw0TZC2Mb/content/id/30798135/do12013-07-23-portaria-n-96-de-18-de-julho-de-2013-30798127

Capistrano, L. F. D., Macêdo, G. C., Pinheiro, M. D., Costa, M. C. da \& Silva, T. F. da (2013) Memória minha comunidade: Lagoa Azul. Natal: SEMURB. [GS Search]

Carvalho, M. L. B. de, Chaimowicz, L. \& Moro, M. M. (2013). O Pensamento computacional no ensino médio mineiro. In: J. P. M. de Oliveira \& P. A. Tedesco (Eds.). Anais do XXI Workshop sobre Educação em Computação (pp. 641-650). Sociedade Brasileira de Computação. [GS Search]

Conforto, D., Cavedini, P., Miranda, R., \& Caetano, S. (2018). Pensamento computacional na educação básica: interface tecnológica na construção de competências do século XXI. Revista Brasileira de Ensino de Ciências e Matemática, 1(1). doi: 10.5335/rbecm.v1i1.8481. [GS Search]

Fernandes, M. J. da S. \& Mendonça, S. G. de L. (2015). PIBID/UNESP: novos sentidos para a formação docente. In: I. M. S. de Farias, M. S. L. Lima, M. M. D. Cavalcante \& J. A. M. de Sales (Eds.). Didática e a Prática de Ensino na relação com a formação de professores. EdUECE. [GS Search]

Ferreira, A. C., Melhor, A., Barreto, J., de Paiva, L. F., \& Matos, E. (2015). Experiência prática interdisciplinar do raciocínio computacional em atividades de computação desplugada na educação básica. In: C. S. de Menezes \& E. Ferraz (Eds.). Anais do XXI Workshop de Informática na Escola (pp. 256 - 265). Sociedade Brasileira de Computação. doi: 10.5753/cbie.wie.2015.256 [GS Search]

Freire, P. (2006). Educação e mudança (M. Gadotti \& L. L. Martin, Trad.). 29 ed. Editora Paz e Terra. [GS Search]

Freitas, H. C. L. (1996). O trabalho como princípio articulador na prática de ensino e nos estágios. Campinas: Papirus. [GS Search] 
Gaspar, M. de L. R., Ribeiro, E. A., Silva, K. G. (2013). O ensino de computação, o PIBID e a formação inicial: primeiras aproximações com o objeto de estudo. In: Anais do II Colóquio Nacional: a produção do conhecimento em Educação Profissional. IFRN. Disponível em: https://ead.ifrn.edu.br/portal/wpcontent/uploads/2012/coloquio/anais/eixo1/Maria\%20de\%20Lourdes\%20Ribeiro\%20Gaspa r.pdf. [GS Search]

Imbernón, F.(2006) Formação docente e profissional: formar-se para a mudança e a incerteza (2. ed.). São Paulo: Cortês. [GS Search]

Marinho, A. R. D. S., de Morais, P. S., de Souza, G. R., \& do Nascimento, A. S. (2018). Relato de Experiência Vivenciada no PIBID sobre a Utilização da Computação Desplugada, a Hora do Código e do Scratch no Ensino Médio. In: L. Galvão \& S. Martins (Eds.). Anais do XXVI Workshop sobre Educação em Computação. Sociedade Brasileira de Computação. doi: 10.5753/wei.2018.3507 [GS Search]

Martinhago, A. Z; Samarzaro, R., Lima, I., Guimarães, L. (2014). Computação Desplugada no Ensino de Bando de Dados na Educação Superior. In: Anais do XXXIV Congresso da Sociedade Brasileira de Computação. Sociedade Brasileira de Computação. [GS Search]

Pimenta, S. G., Ghedin, E. (2005). Professor reflexivo no Brasil: gênese e crítica de um conceito. São Paulo: Cortez. [GS Search]

Pretto, N., Souza, J. S., Rocha, T. B. (2011). Tabuleiro digital: uma experiência de inclusão digital em ambiente educacional. In: N. Preto \& M. H. Bonilla (Ed.). Inclusão digital: polêmica contemporânea (pp. 163-182). Salvador: EDUFBA. [GS Search]

Raabe, A. L. A., Frango, I., Ribeiro, L., Granville, L. Z., Salgado, L., da Cruz, M. J. K., \& Fortes, S. (2017). Referenciais de formação em computação: Educação básica. Porto Alegre: Sociedade Brasileira de Computação. [GS Search]

Ramalho, B. L., Nuñez, I. B., Gauthier, C. (2003). Formar o professor-profissionalizar o ensino: Perspectivas e desafios. Editora Sulina. [GS Search]

Santos, I. (2015, dez. 28). Bem-vindo ao Mundo da Robótica. Robótica na Escola. Disponível em: http://www.roboticanaescola.com.br

Sarmento, A., Farias, M., \& Santos, H. (2017). Relato de Experiência do PIBID: Promovendo o Ensino de Computação de forma interdisciplinar com Português no Ensino Fundamental. In J A. de C. Filho (Ed). Anais do XXIII Workshop de Informática na Escola. Sociedade Brasileira de Computação. doi: 10.5753/cbie.wie.2017.313. [GS Search]

Silva, M. G. L. da; Barroso, M. T. (2010). Caracterização de laboratórios escolares de química em escolas públicas em natal. Revista Educação em Questão, 37 (23), 121-145. Natal: EDUFRN. [GS Search]

Tardif, M. (2012). Saberes docentes e formação profissional (14 ed.). Editora Vozes. [GS Search]

Tripp, D. (2005). Pesquisa-ação: uma introdução metodológica. Educação e pesquisa, 31 (3), 443 466. doi: 10.1590/S1517-97022005000300009. [GS Search]

Vaillant, D., Marcelo, C. (2012). Ensinando a ensinar: as quatro etapas de uma aprendizagem. Curitiba: Editora UTFPR. [GS Search]

Valente, J. A. (2008). Informática na educação: conformar ou transformar a escola. PERSPECTIVA, 24, 21-49. doi: 10.5335/rbecm.v1i1.8481. [GS Search]

Vieira, A., Passos, O., Barreto, R. (2013). Um Relato de Experiência do Uso da Técnica Computação Desplugada. In: $n$ : J. P. M. de Oliveira \& P. A. Tedesco (Eds.). Anais do XXI 
Workshop sobre Educação em Computação (pp. 671-680). Porto Alegre: Sociedade Brasileira de Computação. [GS Search]

Wing, J. M. (2006). Computational Thinking. Communications of the ACM, 49 (3), 33-35. doi: 10.1145/1118178.1118215. [GS Search]

Zanini, A. S.; Raabe, A. L. A. (2012). Análise dos enunciados utilizados nos problemas de programação introdutória em cursos de ciência da computação no Brasil. In: A. M. R. Vincenzi, J. P. M. de Oliveira \& E. J. Spinosa (Eds). Anais do Workshop sobre Educação em Computação. Porto Alegre: Sociedade Brasileira de Computação. [GS Search] 